\section{Noninvasive Measurement of Mouse Myocardial Glucose Uptake with ${ }^{18}$ F-FDG}

TO THE EDITOR: I read with interest the recent publication by Thorn et al. (1) using vena cava image-derived input functions for quantification of myocardial glucose uptake (MGU). The authors demonstrated that using vena cava PET image-derived input functions permits reproducible noninvasive measurement of regional MGU using ${ }^{18} \mathrm{~F}-\mathrm{FDG}$ and Patlak kinetic modeling and shows the expected reduction of MGU in type 1 diabetic mice. However, for accurate quantification of MGU, it is critical that plasma glucose time-activity curves be used rather than wholeblood time-activity curves. As discussed previously in this journal $(2,3)$, whereas glucose equilibrates extremely rapidly across the erythrocyte plasma membrane in primates, this is not true in adult nonprimates $(4,5)$. Transport of glucose into human erythrocytes was too fast to measure at $37^{\circ} \mathrm{C}$, whereas in rat erythrocytes transport was more than 3 orders of magnitude slower, even when compared with human erythrocytes at $4^{\circ} \mathrm{C}$ (5). Slower glucose transport rates result in lower erythrocyte-to-plasma glucose distribution ratios in nonhuman primates; ratios ranged from 0 in pigs to 0.45 in calves (4). More recently, Wu et al. confirmed that ${ }^{18} \mathrm{~F}$ FDG transport was also slow in mice; the ${ }^{18} \mathrm{~F}-\mathrm{FDG}$ concentration in plasma was initially significantly higher than in whole blood and did not reach steady state until approximately $20 \mathrm{~min}$ after injection (6). There was little animal-to-animal variability; estimation of plasma ${ }^{18}$ F-FDG from whole blood values was possible using an empirically derived exponential function, but this would need validation for different experimental conditions such as diabetes (6).

The slow transport of ${ }^{18} \mathrm{~F}-\mathrm{FDG}$ across the erythrocyte plasma membrane also has implications for the lumped constant (LC) of 0.67 used by Thorn et al. to account for differences in uptake and phosphorylation of ${ }^{18} \mathrm{~F}$-FDG versus glucose. As discussed previously $(2,3,7)$, the study by Ratib that established the widely used value of 0.67 for the LC calculated MGU as the product of plasma glucose and myocardial blood flow, assuming equal plasma and whole-blood glucose concentrations and rapid equilibration of glucose across the erythrocyte (8). However, whereas this would be valid in primates, in dogs the erythrocyte glucose concentration is much lower than the plasma glucose concentration, $1.5 \mathrm{mM}$ versus $4.4 \mathrm{mM}$ (9), and the erythrocyte glucose transport rate much slower than cardiac glucose uptake, and so cardiac glucose utilization is essentially derived exclusively from the plasma compartment. MGU can therefore be estimated as the product of plasma flow and the arteriovenous plasma glucose concentration difference (7). Using whole-blood flow to calculate MGU will result in artificially high values, resulting in underestimation of the LC. Kofoed et al. found an LC of 1.1 in healthy dogs using plasma flow to calculate MGU (7). Estimates of the LC obtained in human volunteers ranged from 1 during insulin infusion to 1.4 in the fasted state (10).

COPYRIGHT (c) 2014 by the Society of Nuclear Medicine and Molecular Imaging, Inc.
In summary, for nonprimates slow transport of glucose across the erythrocyte membrane makes it critical to use plasma rather than whole-blood ${ }^{18}$ F-FDG time-activity curves when determining MGU rates with ${ }^{18} \mathrm{~F}-\mathrm{FDG}$ and PET. The value of 0.67 for the LC used to account for differences in the uptake and phosphorylation of ${ }^{18} \mathrm{~F}$-FDG versus glucose is an underestimate, which will result in overestimation of MGU.

\section{DISCLAIMER}

The views expressed are those of the author and do not necessarily reflect those of the National Heart, Lung, and Blood Institute.

\section{REFERENCES}

1. Thorn SL, deKemp RA, Dumouchel T, et al. Repeatable noninvasive measurement of mouse myocardial glucose uptake with ${ }^{18} \mathrm{~F}$-FDG: evaluation of tracer kinetics in a type 1 diabetes model. J Nucl Med. 2013;54:1637-1644.

2. Buxton DB. Glucose permeability in nonprimate erythrocytes [letter]. J Nucl Med. 1999;40:2125-2126.

3. Green LA, Gambhir SS. Glucose permeability in nonprimate erythrocytes [reply]. J Nucl Med. 1999;40:2126.

4. Somogyi M. The distribution of sugars and rate of glycolysis in the blood of some mammals. J Biol Chem. 1933;103:665-670.

5. Wagner R, Zimmer G, Lacko L. An interspecies approach to the investigation of the red cell membrane glucose transporter. Biochim Biophys Acta. 1984;771:99-102.

6. Wu HM, Sui G, Lee CC, et al. In vivo quantitation of glucose metabolism in mice using small-animal PET and a microfluidic device. J Nucl Med. 2007;48:837-845.

7. Kofoed KF, Schoder H, Knight RJ, Buxton DB. Glucose metabolism in reperfused myocardium measured by $\left[2-{ }^{18} \mathrm{~F}\right]$ 2-fluorodeoxyglucose and PET. Cardiovasc Res. 2000;45:321-329.

8. Ratib O, Phelps ME, Huang SC, Henze E, Selin CE, Schelbert HR. Positron tomography with deoxyglucose for estimating local myocardial glucose metabolism. J Nucl Med. 1982;23:577-586.

9. Higgins PJ, Garlick RL, Bunn HF. Glycosylated hemoglobin in human and animal red cells. Role of glucose permeability. Diabetes. 1982;31:743-748.

10. Ng CK, Soufer R, McNulty PH. Effect of hyperinsulinemia on myocardial fluorine-18-FDG uptake. J Nucl Med. 1998;39:379-383.

\section{Denis B. Buxton \\ NHLBI \\ 6701 Rockledge Dr. \\ Bethesda MD 20892 \\ E-mail:db225a@nih.gov}

Published online Mar. 20, 2014.

DOI: 10.2967/jnumed.113.135152

REPLY: We wish to thank Dr. Buxton for his letter to the editor, describing the effects of red blood cell uptake (plasma-to-wholeblood activity ratio) and transport/phosphorylation of ${ }^{18} \mathrm{~F}-\mathrm{FDG}$ versus glucose (lumped constant [LC]) for accurate quantification of the rate of myocardial glucose uptake (rMGU) in mice. Our study (1) showed that the image-derived blood input function (IDIF) within a region of interest in the mouse vena cava can be used for repeatable assessment of the blood time-activity curve for Patlak kinetic modeling of rMGU in healthy control Friend virus B-type mice. We also demonstrated the utility of this 